\title{
A Study of C-E Translation of China Time-Honored Catering Brand Names from the Eco-Translatological Perspective
}

\author{
Ronghua Lv \\ Xi'an University of Science and Technology, Xian, Shaanxi, 710054
}

Keywords: Eco-translatology; Translation as Adaptation and Selection; multi-dimensional adaptation; China time-honored catering brands

\begin{abstract}
This paper is intended to explore the C-E translation of approximately 100 time-honored catering brands, from the eco-translatological perspective. The author, through this research, proposes corresponding translation strategies and methods for the brand names put in six different categories, and produces the translated brand names with the optimal degree of adaptation and selection, by employing multi-dimensional adaptation and selection, with the guidance of Eco-translatology.
\end{abstract}

\section{Introduction}

China Time-honored Brands, long-standing and well-established, have absorbed the essence of abundant and profound Chinese culture and history. And time-honored catering brands are beautiful flowers rooted and blooming in the garden of China Time-honored Brands and represent the height and depth of Chinese culinary culture. On the background of One Belt and One Road, time-honored catering brands should both entertain customers at home and abroad and expand their overseas market. It is not exaggerating to say that their properly translated brand names play a significant role in their process of entering the international market.However, little systematic study is made on C-E translation of these brand names. No doubt that there is an urgent need to give proper concern to this field.

Luckily, thanks to the 2008 Beijing Olympics, the study concerning C-E translation of China Time-honored Brands has attracted a number of scholars' and translators' attention. The typical cultural features and profound historical connotations of those brands have captured great attention and aroused considerable concern at home. How to carry these famous catering brands forward has become the top priority of numerous Chinese citizens and insiders in the catering industry.

This paper has made a research of C-E translation of China time-honored catering brands and illustrated how the two major principles of Translation as Adaptation and Selection can fit into the C-E translation of these brand names. The author aims to make some contributions to the further study of this field.

\section{The Historical Background of China Time -honored Catering Brand Names and the current situation of C-E Translation of China Time-honored Catering Brand Names}

According to China Time-honored Brand Associations, China Time-honored Brands are the brands which have long history, excellent products, techniques or services and reflect Chinese cultural background and cultural deposits. A China Time-honored Brand is an honored title granted by the Ministry of Commerce of the People's Republic of China to any enterprise in China mainland whose brand has well-deserved reputation and receives wide recognition.

On November 16th, 2006, the Ministry of Commerce published the first list of China Time-honored Brands, which includes 434 brands, covering food processing, drug stores, distilled alcohol producers, department stores and famous old restaurants in 30 provinces and cities all over China. There are approximately 100 catering brands among the 434 time-honored brands. Most of them are located in Beijing, Tianjin, Shanghai, Guangdong, Zhejiang, Shandong and Sichuan. Some catering brands are perfectly popular among consumers at home and abroad. For example, 
“Quanjude” in Beijing, “Goubuli” in Tianjin, “Chenmapo” in Sichuan and “Dechangfa” in Xi' an. It' s a pity that only a small part of catering brands has their translated names in English.

“Quanjude” has been officially translated into "Quanjude Peking Roast Duck—Since 1864” ;

"Goubuli" has been translated into "Go Believe". These translated brand names have aroused a lot of controversy and mixed remarks in the society. In this paper, the author will select the catering brand names as research objects, aiming to discover a new path for the C-E translation of China Time-honored Catering Brands.

\section{The Text features and Classifications of the Time-honored Catering Brands}

A successful brand name at home and abroad reveals some common features:(1) Readability. It indicates a brand name must be easy to read and remember, and sound rhythmic and rhymed. Most brand names consist of no more than three words, which increases their readability. Such brand names include "quan you ", "qu mei ", "shuang ye ”(furniture), “mei de ”, "hai xin ”, "hai er "(electric appliances), "wa ha ha ", "meng niu ", "qing dao ”(food), "bai mao ”, "na ai si ", "li bai " (cleanser) and "ji li ", "zhang an ”, "zhong hua "(automobiles), etc. They are all widely known brands. (2) Identifiability. A brand name shows the category and property of a product. If a brand name can also convey to consumers the experience and feeling of using a product, this brand name is far more satisfactory and preferred by consumers. The brands like "mei ke mei jia ", "xi lin men " and "yijia" can be easily associated with household articles and furniture; "jiang nan bu yi", "shunvwu" and "pantaitai" are apt to be brands of women clothes. "wu liang ye " is likely to be identified as alcohol made from five kinds of crops. "meng niu" is relevant to dairy products and "kang shi fu" is relevant to food and food processing. "ke yan shi "and "zi sheng tang " are prone to be regarded as skin care products. "tai zi " and "li bai " sound like cleaning products. All in all, the above-mentioned famous brands are easy to be identified and associated with their properties by consumers. (3) Cultural or aesthetic values. A successful brand can both be profitable and supported by some cultural and aesthetic conceptions. From the brand name "lan yue liang "(liquid detergent), consumers are able to enjoy the romantic and mysterious ambiance. The brand names "zhong hua" and "hong qi "(automobiles ) are carrying the traditional cultural message and symbolizing the high quality of Chinese automobiles. “欧莱雅” (cosmetics), “si er li ” (clothing) and "ba bao li " (luxury goods) can present a graceful and beautiful image to potential users.It's not exaggerating to say that all the renowned brands achieve their success and attain financial benefits at least in part thanks to their successful branding.

The selected catering brands are named in various ways by their original founders. With decades or a hundred years' growth, some of them have partly changed their names in order to maintain their brand image and promote the sales of their products. Therefore, a research of the C-E translation of these time-honored catering brand names should be conducted by putting them into different groups according to their similarities and characteristics.

The selected brand names can go into 6 different categories according to their naming characteristics. They are: (1) brand names made up of proper nouns: founders or birthplaces (2) brand names made up of common nouns plus general names (3) brand names made up of proper nouns plus general names (4) brand names with historical and cultural connotations (5) brand names with auspicious words and (6) other brand names. For the convenience of research, when a brand name cannot go into the previous 5 categories, it will belong to the 6th category. By making the classification, the author is intended to find out the unique translation methods and strategies for every category. 


\begin{tabular}{|c|c|}
\hline Classifications & Brand Names \\
\hline $\begin{array}{l}\text { 1. brand names made } \\
\text { up of proper nouns: } \\
\text { founders } \\
\text { birthplaces }\end{array}$ & 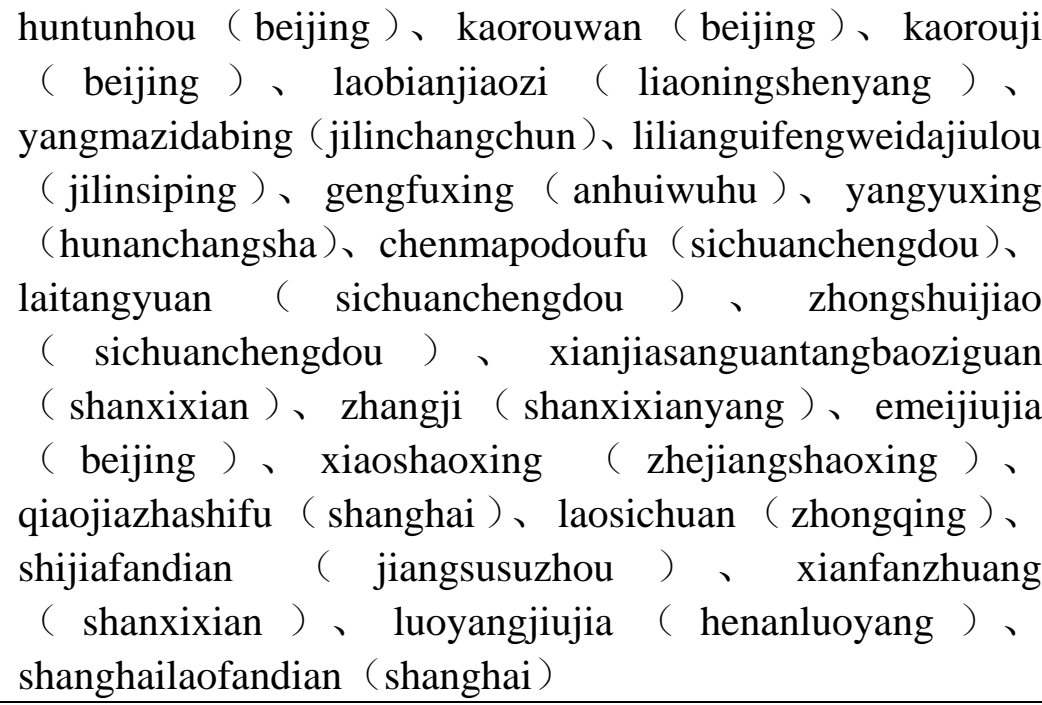 \\
\hline $\begin{array}{l}\text { 2.brand names made } \\
\text { up of common nouns } \\
\text { plus general names }\end{array}$ & $\begin{array}{l}\text { liuquanju (beijing)、shaguoju(beijing)、 tingliguan(beijing)、 } \\
\text { ganlujiaoziguan (liaoningshenyang)、 fuyuanguan(jilin)、 } \\
\text { xinghualou (shanghai)、canglangting (shanghai)、lvyangcun } \\
\text { (shanghai)、deyuelou (jiangsusuzhou)、songhelou (beijing)、 } \\
\text { lvliuju (jiangsunanjing)、 yongheyuan(jiangsunanjing)、 } \\
\text { diyilou (henankaifeng) 、 qingzhendiyichunbinguan } \\
\text { (hunanchangde) 、 wuyifandian(shanxixian) } \\
\text { xinyadajiudian(shanghai) }\end{array}$ \\
\hline $\begin{array}{l}\text { 3. brand names made } \\
\text { up of proper nouns } \\
\text { plus general names }\end{array}$ & 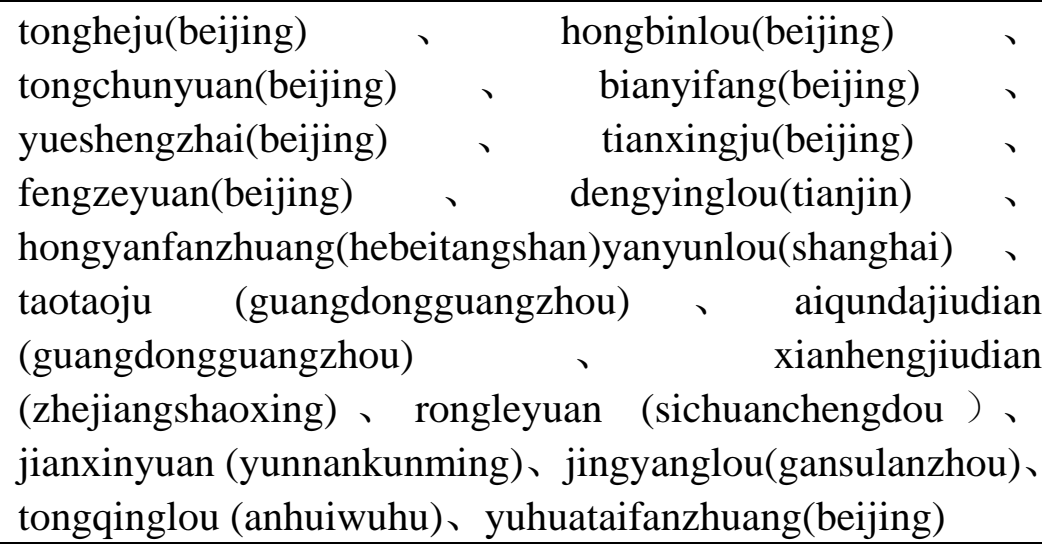 \\
\hline $\begin{array}{l}\text { 4.brand names with } \\
\text { historical and cultural } \\
\text { connotations }\end{array}$ & 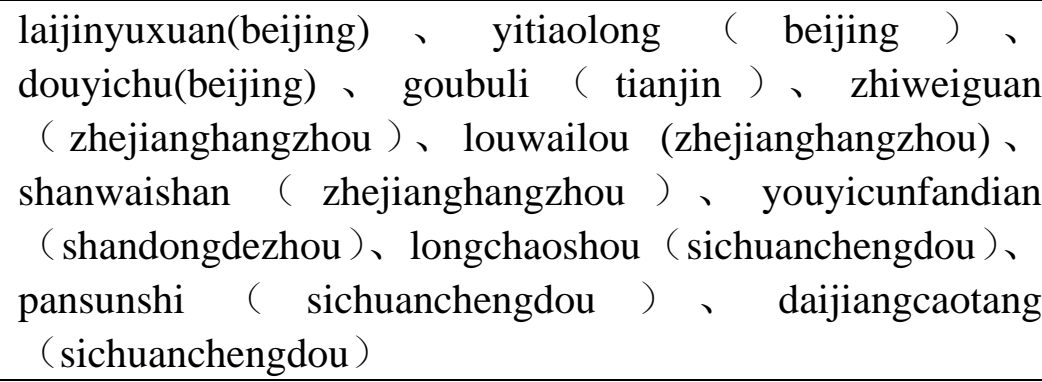 \\
\hline $\begin{array}{l}\text { 5.brand names with } \\
\text { auspicious words }\end{array}$ & $\begin{array}{l}\text { youyishun (beijing)、 quanjude ( beijing )、 donglaishun } \\
\text { ( beijing )、 hongqishun ( tianjin )、 dingfengzhen } \\
\text { (jilinchangchun)、 haoqingxiang (fujianxiamen)、 jufengde } \\
\text { (shandongjinan) defachang (shanxixian) }\end{array}$ \\
\hline 6.other brand names & $\begin{array}{l}\text { qishilin (tianjin)、yuloudong (hunanchangsha)、zhenbutong } \\
\text { ( henanluoyang)、yizhishi ( zhongqing)、 fuqifeipian }\end{array}$ \\
\hline
\end{tabular}




\section{The Adaptation and Selection of the Eco-translatology and the Application of this Theory into C-E Translation of China Time-honored Catering Brand Names}

Eco-translatology is an interdisciplinary translatological research, proposed by Professor $\mathrm{Hu}$ Gengshen in 2001. According to Eco-translatology, translation is a process during which a translator should adapt to the translational eco-environment and be dominated by this environment.Professor Hu illustrates (2008) how a translator produces his/her translated text as follows: A translated text is produced in two phases: "nature" selects a translator and "nature" selects a translated text (See the diagram).

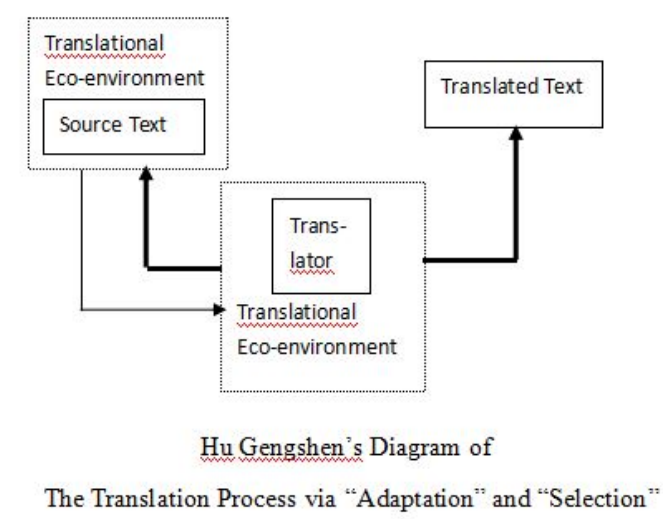

Here, "nature" indicates "translational eco-environment". Based on the theory of "natural selection", in the first phase of "nature" selecting a translator, it is the translational eco-environment in which a source text acts as a typically important component that selects a translator. This phase is regarded as a translator's adaptation to the translational eco-environment, that is, a translator's adaptation. In the second phase of "nature" selecting a translated text, it is the translational environment in which a translator plays the role of a typically important component that selects a translated text. In other words, a translator makes a selection on the behalf of the translational eco-environment and consequently, this selection brings about a translated text.

The author tries to translate the aboved-listed brand names via different methods, from the Eco-translatological perspective.

1. In the translation of the first category, the author suggests Transliteration and Amplification translation. "huntunhou”can be translated into“Mr Hou's Wonton”. These translated brand names are the products of multi-dimensional adaptation. From the lingustic dimension, they convey the principal linguistic information; from the communicative dimension,they definitely show to the readers the products of the catering brands, which helps to attract the prospective customers; from the cultural dimension, the translated brand names with"Mr" or "Uncle", can convey some background information to the readers. According to Tripadvisor, two restaurants are named like "Russ \& Daughters" and "Patzeria Family \&Friends". This way of naming a restaurant is perfectly acceptable for target-language readers. In view of this, the author selects "Gourmet Food \& Brothers", which can both carry cultural connotations and reflect the business scoped of the catering brands.

2. In the translation of the second category, the author suggests Literal translation, transforming the lingustic information into English directly. Most of the brand names in this category can be properly translated via this method, because in the target language, equivalent nouns can be found and translators have no risk of bringing about cultural conflict and obstacles. "liuquanju” is translated into "Willows \& Spring Restaurant”, "ganlujiaoziguan” is "Sweet Dew Dumpling House” "xinghualou” is "Apricot Blossom Restaurant”, "lvliuju” is "Green Willows Restaurant”, “yongheyuan” is "Ever Harmony Garden” and "diyilou” is "The First Tower"

Compare the two different versions of "liuquanju” and "xinghualou”: "Liuquanju Restaurant" 
and "Willows \& Spring Restaurant”, “Xinghualou Restaurant” and “Apricot Blossom Restaurant”. The former ones are translated via Pinyin translation and the latter ones are via Literal translation. The latter ones are better in translation, in that they are produced via the multi-dimensinal adaptation---linguistic, cultural and communicative.

In the translation of the third category, Pinyin translation is commonly seen. Many translators and researchers view Pinyin translation as a principal approach of translating Chinese brand names. Hu Xiaojiao (2012), from Tianjin Normal University, advocated that Pinyin translation should be put in the first place. For one thing, it contributes to the internationalization of a Chinese brand by revealing Chinese cultural features; for another, it helps to make a Chinese brand distinctive and identifiable. In 2008 when Beijing Olympics was drawing near, six China time-honored brands released their English brand names officially. They are "tongrentang" (Tongrentang Chinese Medicine-Since 1669) “ruifuxiang” (Ruifuxiang Silk—Since 1862), “quanjude” (Quanjude Peking Roast Duck—Since 1864), "wuyutai” (Wuyutai Tea Shop-Since1887), "wangzhihe”

(Wangzhihe Gourmet Food-Since 1669), and “rongbaozhai” (Rongbaozhai Art Gallery-Since 1672). In the six translated brand names, Pinyin translation is employed. The author considers Pinyin translation is also applicable in the C-E translation of China time-honored catering brands. The brands in the third category are made up of proper nouns plus general names. The proper nouns are Chinese-featured nouns, which do not have equivalent words in the target language. Under this circumstance, Pinyin translation can effectively maintain the Chinese features and avoid leading to communicative barriers. "hongbinlou", "tianxingju”, "fengzeyuan", "dengyinglou", "hongyanfanzhuang”, “yanyunlou”, “aiqundajiudian”, "rongleyuan”, “jianxinyuan”, “jingyanglou”, “tongqinglou” and "yuhuataifanzhuang” are respectively translated into "Hongbinlou Restaurant”, “Tianxingju Restaurant”, "Fengzeyuan Restaurant”, "Dengyinglou Restaurant”, "Hongyan Restaurant”, "Yanyunlou Restaurant”, “Aiqun Hotel”, "Rongleyuan Restaurant”, “Jianxinyuan Restaurant”, "Jingyanglou Restaurant” and "Tongqinglou Restaurant”. In terms of "tongheju”, "Tongheju Restaurant" is not a perfect choice. Here, Homophonic translation can be tried. "tong” and “Total” are similar in their first sounds; “和” in Chinese means "harmony” and they sound similar in their first sounds.3. So "Total Harmony Restaurant" is an ideal translation of "tongheju” with the optimal degree of holistic adaptation. It reveals the function of this brand: a place where people can eat and drink and conveys to the target-language consumers its cultural connotation that this restaurant aims to bring total harmonious atmosphere to its consumers. In the translation of "taotaoju", the author also applies this method. "taotao" is similar to "total" in pronunciation. Considering it is a restaurant offering Canton-flavored food, the translated brand name is "Total Canton Restaurant” . In the two above-mentioned catering brands, Homophonic translation is better than Pinyin translation, but it is obvious that a single method is far from satisfactory. A combination of different methods is more desirable in terms of catering brand translation.

4.In the process of translating Category 4, Free translation is the fundamental approach. Because the brand names in this category have cultural connotations and historical origins, a translator is more likely to convey their artistic and cultural features with the help of Free translation. "laijinyuxuan" is translated into "Friends Lounge" instead of "Lai Jin Yu Xuan Lounge” . The reason is that "jinyu" means "new friends" and the origin of this catering brand is relevant to friendship and friends. At the sight of "Friends Lounge” , consumers would naturally associate it with a relaxing place where friends can enjoy their leisurely time together. Therefore, the author prefers "Friends Lounge” , which vividly demonstrates a translator' s adaptation from linguistic, cultural, and communicative dimensions. "zhiweiguan" means "yuzhiwowei, guanliaobianzhi" . If it is translated into "Zhiweiguan Restaurant" , it merely tells consumers it is a Chinese restaurant and neglects the vocative function of brand names. So the author prefers to translate it into "Look \& Taste”. This translated brand name consists of two sensory verbs, which can produce a vocative effect on the readers in the target language. This brand name is more likely to arouse consumers' 
interest and stimulate their consuming desire.

"pansunshi" has got its name from Du Fu' poem "qiushu” , which endows this brand with some cultural and historical connotations. This name can be translated into "Pansunshi Restaurant" via Pinyin translation and Amplification translation. But the author selects a better one via Free translation "Yum Plate" . "pansun" in Chinese refers to the plate in which food is served. With the intention to maintain the cultural meaning of "pansunshi" and emphasize the good taste of the product, the author prefers to make it "Yum Plate". From the word "Plate", consumers can easily infer it is a restaurant. "Yum plate" is the outcome of selective adaptation and adaptive selection.

5. Pinyin translation and amplification translation are applicable in the translation of Category 5. The brand named are made up of auspicious words, like "youyishun” , “donglaishun” , "dingfengzhen", "haoqingxiang” and "defachang”. If they are translated via Pinyin translation alone, consumers must be confused, due to their failure to understand and pronounce Chinese Pinyin. Therefore, Amplification translation is by all means a supplementary method. "youyishun" is "Youyishun Muslim Restaurant” , “donglaishun” is "Donglaishun Muslim Restaurant” , “dingfengzhen” is "Dingfengzhen Dim Sum Shop”, "haoqingxiang” is "Aroma Restaurant” and "defachang" is "Defachang Dumpling Banquet" . By adding the words "restaurant" , "Muslim”, "dim sum”, “dumpling banquet, the author conveys the specific functional information to the target language consumers. This kind of English brand names are informative and vivid for consumers. They are the products of selective adaptation and adaptive selection made by the translator. During the translational process, a translator plays a leading role and is the center of the translational process.

6. In terms of the brands in Category 6, “yizhishi” and "zhenbutong” are translated via Free translation. In the brand name "yizhishi", "yi" in Chinese means "cheeks". As we know, people move the muscles on their cheeks quickly when they eat the yummy food they like. Naturally, we can infer that "yizhishi" means "the joyful time" when an eater enjoys his food. Considering from the communicative and linguistic dimensions, the author prefers the translated name "Dining Time” , which sounds concise, melodious, impressive and easy to be memorized. "zhenbutong” means "totally different" in English, but if this brand is translated this way, it sounds somewhat weird and awkward as a brand name. In view of this, the author tries to put it into "Gramercy Restaurant" . According to the data from Tripadvisor, one of the top 100 restaurants in New York is named “Gramercy Tavern" . "Gramercy" is an interjection, meaning "great!" It sounds like someone' s praise with loud shouts of applause. Therefore, "Gramercy Restaurant" and "zhenbutong" can exert the same positive effect on their potential consumers in different languages.

\section{Conclusion}

The paper explores the application of Eco-translatology into the C-E translation of China Time-honored catering brand names, from the perspective of a translator's adaptation and selection. Through this research, the author concludes that a translator should make selective adaptation and adaptive selection in the translation of any category of China time-honored brand names. The author, via this interdisciplinary approach, produces translated brand names for the six categories and proposes some corresponding translation methods. This research is trying to do initial work for the normalization and standardization, hoping to make some contributions to the future of C-E translation of China Time-honored Brands. 


\section{References:}

[1] Hu, Gengshen. (2003).Translation as Adaptation and Selection. Perspectives:Studies in Translatology (4):283-291.

[2] Chen, Quanming.(1996). On the Translation Approaches and Skills of the Imported Brand Names. Chinese Science and Technology Translators Journal (1):11-13

[3] Hu, Gengshen.(2004).Translation as Adaptation and Selection.Wuhan: Hubei Education Press.

[4] Hu,Gengshen.(2006).Interpreting the Translation Theory from Translated Texts---the Translated Cases via TAS. Foreign Language Education(4):50-54

[5] Hu,Gengshen.(2008). Interpreting the Translation Theory from Translation Terms---an Overview of Translation as Adaptation and Selection. Shanghai Journal of Translators(2):1-5

[6] Hu,Gengshen.(2008).Interpreting Eco-translatology. Chinese Translators Journal.(6):11-15 